\title{
Ars moriendi
}

\section{Erhard Taverna}

Dr. med., Mitglied der Redaktion

Bei Seneca hiess das noch: «Wer die Menschen sterben lehrte, der würde sie zugleich auch leben lehren.» Michel de Montaigne schrieb in seinen Essais: «Philosophieren heisst sterben lernen.» Kein morbider Todestrieb. Doch eine sträflich vernachlässigte Lebensweisheit, vor allem in der modernen Medizin. Die Impulse kamen von aussen, etwa von Elisabeth Kübler-Ross oder Peter Noll, dann lehrte die WHO mit Schmerzmitteln differenzierter und grosszügiger umzugehen, und schliesslich zwingt die Altersdemographie über Palliativmedizin und Sterbehilfe nachzudenken. Die Gerontologie segelt im stürmischen Wind der Widersprüche. Der Genomforscher Craig Venter hat die Firma Longevity Inc. gegründet, und auch das Biotechnologieunternehmen Calico (California Life Company) von Google will uns länger und gesünder am Leben erhalten. 200 Jahre Langeweile? Als Erwachsener mit den Urgrosseltern auf das neue Jahr anstossen? Im Berner Museum für Kommunikation übt man mit Senior Guides den optimistischen Blick auf die Zeit nach der Pensionierung, wo alle so richtig aufblühen.

«Der Tod bleibt das Unzumutbare, dem niemand entkommt, das Skandalon, das durch keinen spirituellen Trostgrund und kein philosophisches Dementi aus der Welt geschafft wird», schreibt der Herausgeber Roger Shatulin im Manesse-Band Der Verlachte Tod [1]. Der Tod versteht keinen Spass, der Mensch aber schon. Der Friedhof als sardonische Amüsiermeile, schwarzer Humor als existentielle Notwehr, Spott auf die letzten Dinge. Heitere Grabinschriften, Nekrologe und Mementos, launisch, lakonisch, schnippisch, schlüpfrig, spöttisch, blasphemisch und zynisch. Von der Antike bis in die Gegenwart, von François Villon bis Robert Gernhardt, von Goethe bis Grass, es kommen jeder und jede auf ihre Rechnung. Im Makabren liegt die Heiterkeit, die Trauer macht das Leben kostbar, etwa mit Peter Rühmkorf: «Auferstehung, leicht gemacht - dank Viagra - gute Nacht». Die geistreichsten Köpfe der Weltliteratur trotzen dem Trübsinn des Todes. Die menschliche Vergänglichkeit erinnert an das hier und jetzt. Eine Medizin gegen Auswüchse der Medizin. Mit der Wegzeh- rung von Günter Grass lässt sich hintersinnig gut leben: «Mit einem Sack Nüsse will ich begraben sein und mit neuesten Zähnen. Wenn es dann kracht, wo ich liege, kann vermutet werden: Er ist das, immer noch er.» Die ganz alltäglichen Todesanzeigen haben es zuweilen auch in sich. Allerdings eher unfreiwillig. Sowohl in den multiplen Anzeigen prominenter Nachrufpersönlichkeiten wie in persönlichen Sinnsprüchen finden sich Stilblüten und intime Zusammenhänge, die erstmals 2009 in gesammelter Form Aus die Maus ihren Weg in die Spiegel-Bestsellerliste fanden. Inzwischen ist nach Wir sind unfassbar der dritte Band Ich mach mich vom Acker [2] erschienen, ein Resultat von Unmengen Post, Briefen, Karten und E-Mails, wie die Herausgeber schreiben. Grosse Gefühle, Rätselhaftes, Skurriles und sehr viel Komik, tröstende Erkenntnis und befreiendes Lachen. Die besten Fundstücke finden sich dort, wo auf Hilfestellungen der Zeitungen oder des Internets, zugunsten Schilderungen der eigenen Gefühlslage, verzichtet wird. Nicht einfach, denn der Platz ist knapp. Die persönliche Note widerspiegelt die vielseitig veränderten Bestattungsformen. Neben vielen gelungenen Beispielen kann das auch ganz schön daneben gehen, wie Tausende Beispiele zeigen. Es sind Kleinstgeschichten auf wenigen Quadratzentimetern vom Leben und Lieben, aus Deutschland, Österreich und der Schweiz. Manchmal sind es Trouvaillen, die mehr über die Hinterbliebenen verraten, als ihnen lieb sein kann: «Nun ist endlich Schluss. Der Mittelpunkt unserer Familie hat uns verlassen.» Zornige Ergüsse kommen vor, Familienstreitereien werden ausgetragen, Hobby und Beruf finden Platz: «Das sportlichste Mitglied unserer Familie wurde von seiner Krankheit überholt. Hans M. läuft nicht mehr» oder "Er hat die Lampen in seinem Fachgeschäft nach 50 Jahren ausgeschaltet.»

Vergleiche können arg hinken: «Beherzt wie eine Briefmarke, ging er seines Weges.» Eine Todesanzeige vermerkt schlicht und einfach: «Wer nicht stirbt - hat nie gelebt.» Vordergründig banal und dennoch weise, denn «Es gibt ein Leben vor dem Tod» hat uns Wolf Biermann in den 1970ern vorgesungen. verlachte Tod, Zürich Manesse Verlag; 2015.

2 Nöllke $M$, Sprang C. Ich mach mich vom Acker, Köln: Kiepenheuer und Witsch; 2013.

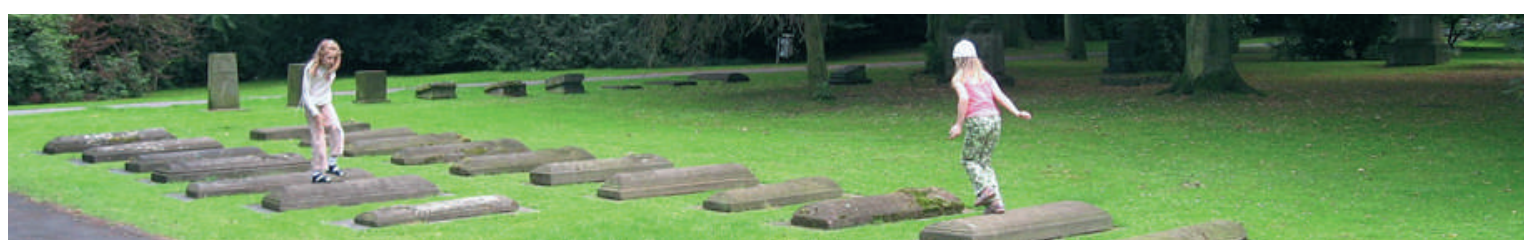

